\title{
Research Economic Evaluation of Offshore Article Wind Power in the Liberalized Dutch Power Market
}

\author{
Junying Chang*, Shell Energy Europe, 1 3 Strand, London, WC2N 5HR, UK \\ Bart C. Ummels, Delft University of Technology, The Netherlands \\ Wilfried G.J.H.M. van Sark, Science, Technology and Society Department, Copernicus Institute, \\ Utrecht University, Heidelberglaan 2, 3584 CS Utrecht, The Netherlands \\ Huub P.G.M. den Rooijen, Shell Energy Europe, The Netherlands \\ Wil L. Kling, Delft University of Technology, Eindhoven University of Technology and TenneT TSO \\ B.V., The Netherlands
}

Key words: wind power; variability; forecast; market integration; energy program responsibility; market value

\begin{abstract}
The variability and limited predictability of wind power challenges the operation of power systems, where the generation and load are required in balance at all times. The transmission system operator (TSO) is the responsible party. In a liberalized energy sector, key technical elements of power system operation have been transferred to markets and are thereby translated into economic responsibilities born by all system parties. The Dutch TSO TenneT operates the 15 min interval real-time system balancing the market platform where energy responsibilities are economically assessed. Market parties subject to programme responsibilities with wind power as part of their generation portfolio must bear the integration costs of wind power's variability and forecast errors. The question arises what the real value of wind power is in the market. In this paper, a straightforward approach is used for the economic evaluation of existing wind power, taking Dutch market as a case study. Factual production data are obtained from a $108 \mathrm{MW}$ offshore wind farm. Two variations of persistence forecast model are applied for the assessment of wind power value, which is quantified using price data on the Dutch wholesale markets and the TSO's balancing market. It is found that presently in The Netherlands, wind power is a price-taker with a value equalling $90-110 \%$ of averaged market prices, including the imbalance cost component. The right-skewed distribution of APX (Amsterdam Power eXchange) spot market prices is found to reduce the market value of wind power. The impact of forecast errors on overall wind power value is low due to the small impact of wind power on short-term wholesale market prices. Copyright $\odot 2009$ John Wiley \& Sons, Ltd.
\end{abstract}

Received 15 April 2008; Revised 11 March 2009; Accepted 13 March 2009

\section{Introduction}

Security of energy supply and environmental concerns have been and are driving renewable energy developments worldwide, whereby wind energy has experienced one of the largest growth rates in the past decades. Technology development and learning experience have contributed directly to the upscaling of wind turbines and to the proportional investment cost reductions for new wind parks. Higher wind resources and a wider availability of locations have driven wind power offshore, whereas additionally offshore wind park

\footnotetext{
* Correspondence to: J. Chang, Shell Gas Direct Ltd, 1 3 Strand, London, WCZN 5HR, UK.

E-mail: junying.j.chang@shell.com
} 
developments are accelerated by advancements in offshore engineering. Large-scale offshore wind parks enable the further growth of wind power in the next decade, which is necessary in order to reach the targets for $\mathrm{CO}_{2}$ emission reduction and deployment of renewables set by the European Union. ${ }^{1}$ European targets include $180 \mathrm{GW}$ installed in 2020 (of which $60 \mathrm{GW}$ are offshore), with present levels already around $57 \mathrm{GW}$ (1 GW offshore) supplying $4 \%$ of electricity consumption. ${ }^{2}$

Integration of large-scale wind plants into power systems is challenging for power system operation. Power generation and consumption in the system must be constantly balanced in real time, since electric power cannot be stored in significant amounts. When wind power is integrated, additional reserves from conventional thermal units are usually allocated to accommodate wind power. The variability and limited predictability of wind power makes the optimization of generation unit planning (commitment and dispatch) more difficult. The additional reserves for wind power are associated with an economic cost, which is generally known as 'imbalance cost'. When wind power is integrated into liberalized markets, depending on the national supporting scheme, imbalance cost can have an impact on market revenues received by the wind park owner from wind power. In the Dutch, ${ }^{3}$ the Spanish $^{4}$ or the British ${ }^{5}$ market, imbalance costs are borne by the park owners, hence it is critical for these parties to understand the costs. Under feed-in tariffs such as those applied in Germany, balancing costs are transferred by the transmission system operator (TSO) to the end consumers, hence park owners are less concerned with this particular element. ${ }^{6}$

Comprehensive economic studies concerning imbalance cost of wind power agree that upon increasing wind power penetration imbalance costs increase as well. At wind power penetration levels of up to $10 \%$ of annual consumption, the balancing cost associated with wind power are estimated to be 1-3.9 EUR $\mathrm{MWh}^{-1}$; at higher penetration levels up to $30 \%$, this cost estimate is $2-4.6 \mathrm{EUR} \mathrm{MWh}^{-1}{ }^{5-9}$ However, little research has been directed towards the actual commercial imbalance costs incurred by an individual wind park operator in a specific liberalized market. In fact, it is the non-transparency of commercial imbalance costs that frequently hinders wind park developers to arrive at balanced wind power supply agreements with market parties, implying additional investment risk.

This paper uses a market-based approach and a case study to investigate to what extent imbalance cost will affect the power value as a commodity in a liberalized market. The market revenues of the recently installed Offshore Wind park Egmond aan Zee (OWEZ) were derived using actual market prices assuming that the generated power output would be sold directly to the liberalized Dutch market. Located 10 to $18 \mathrm{~km}$ west from the Dutch coast, the OWEZ comprises 36 Vestas V90 wind turbines and has an installed capacity of 108 MW supplying renewable electricity for about 100,000 Dutch households. ${ }^{10}$ From October 2006 to May 2007, 8 months of wind power production data (10 min values) are obtained from the OWEZ as well as price data from the liberalized market platforms to where the electricity may be sold. An economic assessment Excelbased model is built taking into account different wind power forecast ('forecast' and 'prediction' have the same meaning in the paper and are interchangeably used) variations and the characteristics of the different markets. The model evaluates the commercially realistic value of wind power, in the presence of imbalance responsibility and market forces.

The paper is organized as follows: firstly, the essential concepts of the Dutch power market design are presented with a special focus on wind power. Secondly, the economic evaluation methodology is developed, including an analysis of market power prices and the development of a wind power evaluation model. Thereafter the model results and analysis are described. The final section presents the conclusions of this paper and provides an outlook on further research.

\section{Market Integration of Wind Power}

Since electric power cannot be stored in significant quantities, power system operation requires a continuous balance between generation and demand. Conventional generation technologies allow sufficient possibilities for controlling their output and power system balancing evolves around the continuous, real-time adjustment of generation units to match the load. The responsibility for maintaining the power balance lies with the TSO; 
in The Netherlands it is TenneT. In order to balance the system, TenneT applies power reserves made available by market parties. To guarantee sufficient power reserves for reliable power operation, TenneT contracts power reserves from market parties and uses a real-time power balancing market to settle system imbalance. This real-time balancing market provides market parties with economic incentives to adjust their operation set points to an economically optimized level such that power imbalances occurring in real time are minimized.

In liberalized markets, parties buying and selling electrical energy have become free to make trading arrangements. Electricity markets are designed such that electricity can be traded just like any other commodity at the same time guaranteeing that power balance is maintained in real time. In order to do so, TenneT applies the system of program responsibility: Dutch market parties or program responsible parties (PRPs) are responsible for keeping their own energy balance, ${ }^{3}$ which are laid down in the energy programs (e-program) that specify the net-energy exchange with the system for each 15 min settlement time [program time unit (PTU)]. TenneT receives all e-programs from the PRPs 12 to $36 \mathrm{~h}$ ahead of operation and requires a $100 \%$ balanced e-program. E-programs may be changed up until $1 \mathrm{~h}$ ahead of operation by trades on the adjustment market if enough economic liquidity exists. PRPs may also bid in excess or deficit power capacity into the regulating and reserve power market, which also closes $1 \mathrm{~h}$ ahead of operation. ${ }^{11}$

The system of program responsibility is backed by assigning prices to e-program deviations, the so-called imbalance pricing mechanism. Since e-programs are all $100 \%$ balanced, any power imbalance occurring in real time is the result of unscheduled power exchanges with the system, which must be counterbalanced to zero. The power reserves used by TenneT for system balancing are settled against the price of the highest bid that is used: the PRP deviating from its schedule pays this price to TenneT, and TenneT pays this price to the PRP delivering the excess/deficit power activated as reserves by TenneT. It should be noted that all e-program deviations are settled with the imbalance price: passive contributions to power system balancing are rewarded as well. The incentives provided by the imbalance pricing mechanism encourage PRPs to continuously monitor and control their power balance.

In The Netherlands, wind power is considered as a generation technology just like conventional generation: wind power is sold by PRPs on electricity markets (mostly spot market) and is subject to program responsibility. Thus, balancing the limited predictability and variability of wind power is the responsibility of PRPs with wind power in their generation (and load) portfolio rather than the TSO. PRPs therefore must consider their balancing costs from keeping additional power reserves for balancing wind power in relationship to the imbalance price. It can be noted that the imbalance price is set during each separate PTU and can therefore not be predicted. At present, interviews with the main Dutch PRPs have revealed that PRPs opt for the risk-averse strategy to balance wind power using their own portfolio. The optimal strategy, however, depends on many factors, including the characteristics of generation and load within the particular PRP portfolio, measurement accuracy of the portfolio, expected wind power production, forecast errors and the imbalance price.

Also, the total wind power capacity installed in The Netherlands has an impact on the operating strategy of PRPs, especially considering the high correlation of wind pattern at different wind park locations in this small geographical area. By mid 2008 approximately 1900 MW wind power has been installed in The Netherlands, accounting for $8 \%$ of total power generation capacity. ${ }^{12}$ These parks are likely to use similar source of wind speed forecast and hence to follow similar balancing pattern. In the longer term much higher percentage of wind power is expected to be in the Dutch power system as the Dutch government set the targets to install $6000 \mathrm{MW}$ offshore wind by $2020,{ }^{13}$ it can be anticipated that the operating strategies of Dutch PRPs with high volume of wind in their portfolio will change.

\section{Methodology}

\section{Assumption, Parameters and Data}

When wind power is integrated in the Dutch wholesale market and treated equally as power from conventional generation units, its commodity value for the project operator is defined as the sales revenue from each MWh produced. This revenue will be obtained by the operator from the party acting as the PRP on his behalf with the 
amount specified in an energy purchase contract. The PRP usually has a portfolio of generation units including the contracted wind park. In this paper this portfolio is not considered: a PRP is assumed that has only the 108 MW OWEZ wind park as its power generation source. The PRP schedules its wind power output and nominates this to the spot market, whereas the e-program is determined by frequently updated with wind speed forecast and power output prediction and is then sent to the TSO. This PRP is assumed to sell all excess wind power (relative to its MWh volume laid down in the e-program) to the balancing market, and buy all deficit wind power from this market. In operation, the TSO will balance any deviations from the finalized e-program that may occur in real-time and allocate the corresponding imbalance price to the output surplus or deficit.

On the commercial side, four components are of primary interest for a PRP: the contracted energy purchase prices; the market income from energy sales; TSO imbalance cost; and imbalance costs of the PRP by balancing wind power deviations autonomously. The revenue coming from wind power will be based on the actual energy sales of wind production in the market taking into account the cost of balancing deviations from prediction.

Since data on the PRP's autonomous imbalance costs are not available because of the company-sensitive nature of such information and also because of the fact that PRPs frequently do not know their own balance situation in their portfolio, e.g. because there is no real-time metering in domestic customers, this paper only considers the settlement prices published on TenneT TSO's real-time regulating and reserve to calculate wind power imbalance costs. Likewise, the income from wind power sales will be calculated using transparent spot market prices and contract income is not accounted, since sales is the revenue actually obtained by the PRP from wind energy input to the market whereas contract price is confidential. The imbalance cost for wind power is a function of the real-time deviation of wind park output from the e-programme (i.e. prediction error) including direction (+/-) and magnitude, system sell/buy price, and system situation, i.e. long or short. Market income, then, is dependent on two variables: wind park power output; and the market price received for each MWh delivered. Wind power output depends on the wind speeds at the park site and the characteristic relationship between wind speed and wind power of the wind turbines (power curve).

Because of the current low penetration of wind in the Dutch power market, it is assumed that the low marginal generation cost of wind power does not significantly affect the national power pricing dynamics, i.e. wind power is a market price taker.

For this analysis, the price data of general average value were obtained from the Amsterdam Power eXchange (APX) day-ahead market from 1 October 2006 to 31 May 2007. These are hourly prices. Imbalance price data for the same period were downloaded from the TenneT website. These are $15 \mathrm{~min}$ prices. The assessment was based on the 2007 installed wind capacity in The Netherlands (around $1580 \mathrm{MW}$ ) including onshore wind power and the $108 \mathrm{MW}$ OWEZ wind park. All onshore parks were aggregated to be one with a capacity of 1472 MW. The 10 min average production data for the 108 MW OWEZ was obtained for the same period as the APX data (note: these are not public data).

\section{Wind Power Trading Practices on Market Places}

The commodity value of wind power may be optimized by price speculation and arbitrage between different wholesale markets. In theory, wind power can be traded under any type of wholesale contract on the various places with different prices. Generally, markets with structurally higher prices are associated with higher uncertainties and risks. From a wind power selling perspective, wind power should be sold on the combination of markets offering the optimum between market price and market risk exposure. A single power purchase contract for a single wind park is at present very likely to be based on a single price index on one wholesale market rather than on a basket of indices. Taking into account present power trading practices of market parties, among which wind power trading still plays a rather insignificant role, and also taking into account the practicalities of day ahead wind power forecasting, today, wind power is traded on day-ahead markets in many countries. From a wind power point of view, the significant forecast errors present in the associated $12-36 \mathrm{~h}$ ahead scheduling time-frame would, however, suggest trading on a combination between a day-ahead spot and an intra-day adjustment market, if available, allowing the incorporation of more accurate wind power predic- 
tion. ${ }^{14,15}$ During 2007 such an intraday market was introduced in The Netherlands; however, it is not included in this paper.

\section{Analysis of the Impact of Wind Power on Price and Price Volatility}

Having previously stated that wind in Dutch power market is assumed to be a price taker, it is important to test the robustness of this assumption. This is because wind power has a marginal generation cost that is close to zero and will therefore naturally take a priority in the market price bid ladder. This will drive power prices down when its market share has gained a certain magnitude, such as what has been observed in Denmark and Germany. ${ }^{15-18}$ Meanwhile, because of its variability and limited predictability, the power system must physically accommodate real-time wind power output deviations from scheduled values. Large variations of wind power require additional regulating and reserve power for system balancing, which will result in additional price volatility and higher prices on average on the imbalance market. In other words, increasing amounts of large wind power deviations are likely to amplify imbalance price volatilities on real-time balancing market, ${ }^{19}$ which consequently will expose wind power to a higher imbalance cost risk.

The price-taker assumption is tested firstly via assessing the correlations of wind power input in the shortterm market (i.e. APX day-ahead market) and prices. Secondly, this is done via assessing the impacts of wind power variations on balancing market (i.e. TenneT real-time balancing market) prices and volatility. These assessments will determine the level of validity and robustness of results derived from historical data from a commercial and investment perspective.

\section{Correlation between Wind Speed/Production and APX Day-ahead Market Price}

Using the data for the period 1 October 2006 to 31 May 2007 specified earlier, the following correlations between pairs of aforementioned variables are investigated to estimate their linear dependence relationship:

- Correlations between OWEZ hourly average power production and APX spot market hourly price.

- Correlations between OWEZ hourly average wind speeds measured on site and APX day-ahead market hourly price.

The abbreviations of the variables are summarized as follows:

$$
\begin{array}{c|l|l}
E_{t}^{\mathrm{PARK}} & \text { OWEZ hourly power production at time } t & (\mathrm{MWh}) \\
v_{t}^{\mathrm{PARK}} & \text { OWEZ hourly average wind speed at time } t & \begin{array}{l}
\left(\mathrm{ms}^{-1}\right) \\
\left(\mathrm{EUR} \mathrm{MWh}^{-1}\right)
\end{array} \\
P_{i}^{\mathrm{APX}} & \text { APX hourly price for time } t
\end{array}
$$

The analysis of the monthly data shows that there is no linear correlation between the measured power outputs of the OWEZ and APX hourly prices. Also, using wind speed measured at the OWEZ meteorological mast as a rough indicator for the aggregated wind power output in The Netherlands because of the country's relative small size, it was found that there was no linear correlation between wind speed and APX hourly prices. The values of the coefficient of determination $\left(R^{2}\right)$ are all very low indicating no correlation as can be seen from Table I. Figure 1 shows a graphic explanation of how the $R^{2}$ values were calculated. Part of the scatter observed in Figure 1 is because of the use of a single wind speed measurement to represent all wind power production in The Netherlands. This approach thus also contributes to making the value of $R^{2}$ low. Nevertheless, with the relatively low slope of the trend line, it is concluded that wind power still has a minor influence on the APX price. The authors have not identified any other type of correlation in the analysis.

\section{Correlation between the Dutch Wind Power Variations and the TenneT Price Variations}

In reality, instead of dealing with the power output from a single wind park, the Dutch market party acting as the PRP for OWEZ will integrate the gross output of a group of wind parks (along with the output of other power plants). In general, because of the geographical spread resulting in different wind patterns at distant 
Table I. $R^{2}$ values of wind power production/speed at OWEZ park and APX prices

\begin{tabular}{lcccccccc}
\hline & Oct 2006 & Nov 2006 & Dec 2006 & Jan 2007 & Feb 2007 & Mar 2007 & Apr 2007 & May 2007 \\
\hline$E_{\mathrm{t}}$ versus $P_{\mathrm{i}}^{\text {APX }}$ & 0.0031 & 0.0018 & 0.0774 & 0.1254 & 0.0330 & 0.0943 & 0.0214 & 0.0037 \\
$v_{\mathrm{t}}$ versus $P_{\mathrm{i}}^{\mathrm{APX}}$ & 0.0085 & 0.0111 & 0.0878 & 0.0830 & 0.0397 & 0.0606 & 0.0255 & 0.0471 \\
\hline
\end{tabular}
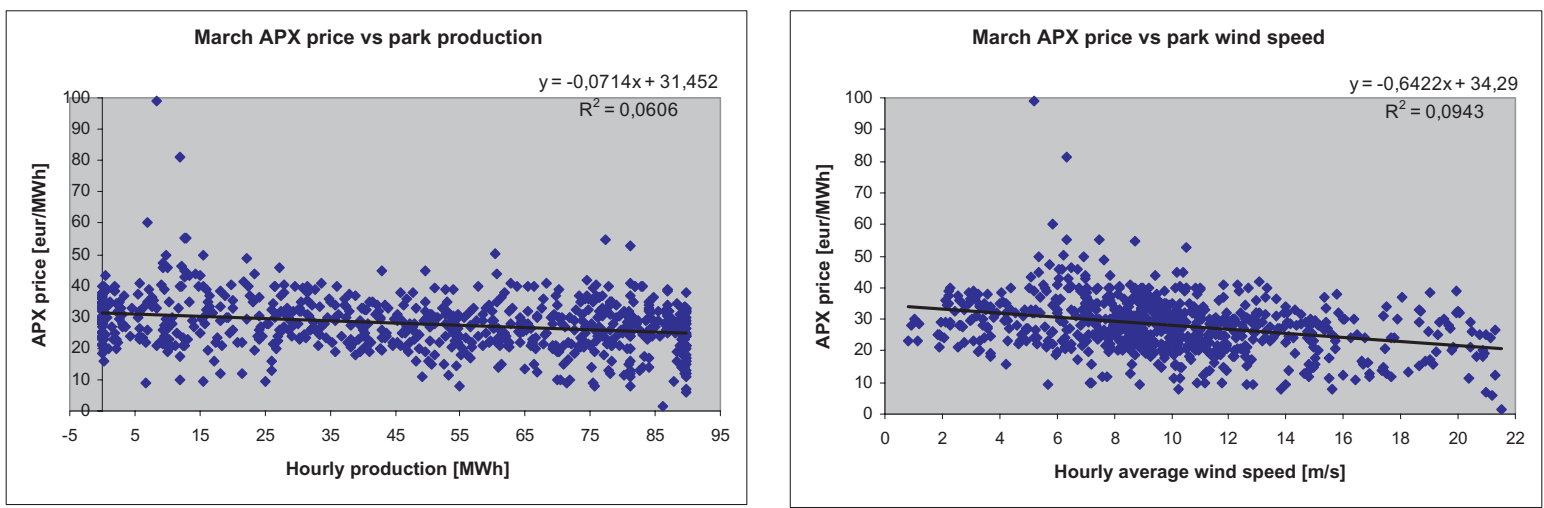

Figure 1. Correlations between APX hourly prices and hourly OWEZ park power production/wind speed

park sites, the aggregated wind power output will be much smoother than a single farm power curve..$^{20,21}$ Even more so, a large geographical spread of wind power will reduce variability and decrease the occurrences of near zero or peak output. ${ }^{22}$ However, this notion is only to a certain extent applicable to The Netherlands considering its rather small geographical size. Nevertheless, it can be argued that wind power variations between different Dutch wind parks can be slightly correlated and thus produce some smoothing effect, which consequently will reduce the stress of system balancing by TenneT, taking into account the short program time unit applied for power balancing (15 min).

To safely assess the influence of wind production variations on balancing prices fluctuation, the conservative yet extreme assumption was made that the total $1580 \mathrm{MW}$ installed wind capacity in The Netherlands would follow the same varying direction as OWEZ. With no aggregate wind power output data available, it was assumed that offshore wind power has a low capacity factor of $25 \%{ }^{12}$ so that the offshore wind power data of OWEZ could be scaled into total wind power output for The Netherlands. The effect of using a higher, more realistic capacity factor, on the analysis below is negligible.

The definitions and abbreviations of the variables are as follows:

$$
\begin{gathered}
\partial E_{\mathrm{t}}=E_{\mathrm{t}}-E_{\mathrm{t}-1} \\
\partial P_{\mathrm{t}}^{\mathrm{SSP}}=P_{\mathrm{t}}^{\mathrm{SSP}}-P_{\mathrm{t}-1}^{\mathrm{SSP}} \\
\partial P_{\mathrm{t}}^{\mathrm{SBP}}=P_{\mathrm{t}}^{\mathrm{SBP}}-P_{\mathrm{t}-1}^{\mathrm{SBP}}
\end{gathered}
$$

where $\partial E_{\mathrm{t}}$ is the aggregated wind power production variation at PTU $t(\mathrm{MWh}) ; E_{\mathrm{t}}$ is the aggregated wind power production in The Netherlands (MWh); $\partial P_{\mathrm{t}}^{\mathrm{SSP}}$ is the TenneT System Selling Price (SSP) variation at PTU $t\left(\right.$ EUR $\left.\mathrm{MWh}^{-1}\right)$; and $\partial P_{\mathrm{t}}^{\mathrm{SSP}}$ is the TenneT System Buying Price (SBP) variation at PTU $t$ (EUR $\left.\mathrm{MWh}^{-1}\right)$.

Scattered wind production variations against TenneT's balancing price variations sampled in Figure 2 clearly explain that the two variables are independent of each other. Both the magnitude and direction of variation are not linearly correlated. This proves that the wind production variation at current installation level does not appear to affect the capability of system balancing. Neither the variations of measured wind speed nor of the 

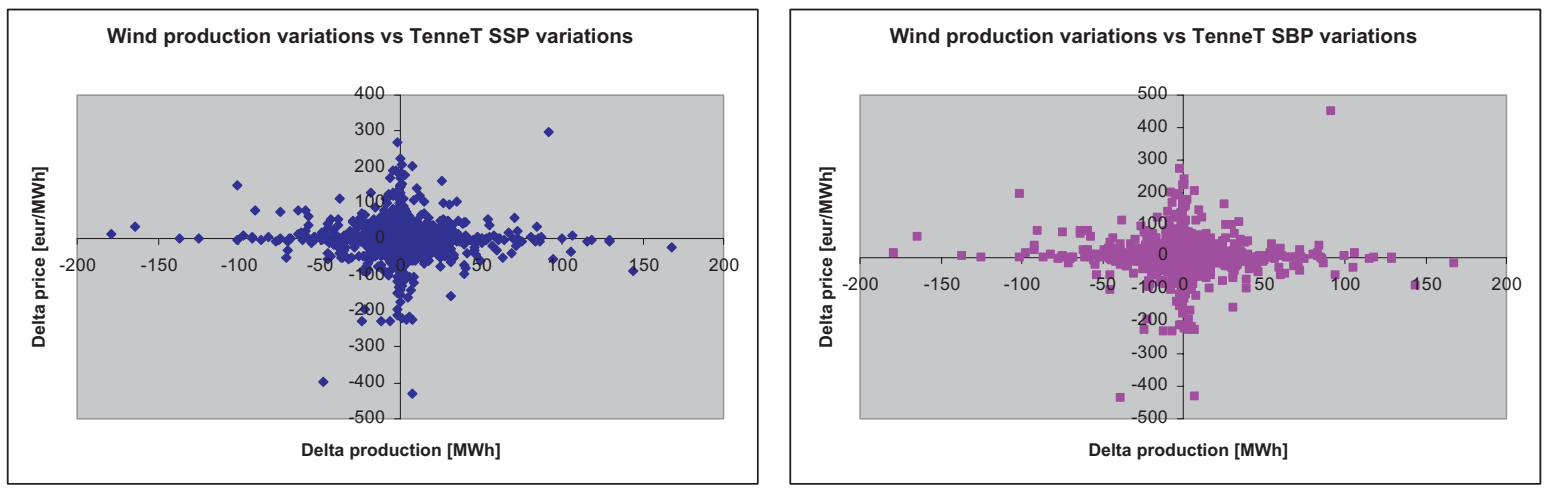

Figure 2. Comparison of wind production variations and TenneT balancing price variations

corresponding wind power production are directly contributing to price fluctuations seen in the short-term trading platforms. This can be explained considering total wind installation in The Netherlands in 2007 was $1580 \mathrm{MW}$, which is $7 \%$ of the total installed generation capacity in The Netherlands. The percentage is even lower when a park capacity factor of $25 \%$ for onshore and $40 \%$ for offshore would be considered. When it comes to the imbalance cost of wind power, it can thus safely be assumed that wind power is a price taker for the data used in this research and that the data can be used to estimate the commodity value of the wind power production of the OWEZ park.

\section{Integrated Assessment Excel-model}

Having tested the robustness of assumption that wind power production does not affect short-term market price and balancing market volatility, a quantitative model is constructed in Excel to integrate market revenue and imbalance cost in order to assess the market value of wind power. The model delivers the result in Euro per MWh unit of energy delivered by the OWEZ park.

\section{Modelling Assumptions}

As previously mentioned, for simplicity and also for the estimation of the economic value of wind power independently, the OWEZ park is assumed to be the sole generation source in an anonymous PRP's portfolio, i.e. the PRP does not have additional generating capacity nor electricity demand at its disposal. It is assumed that the PRP has its wind power sales indexed to the APX day-ahead market. It is also assumed that the optimal revenue from wind power comes from a programme with perfect forecast, i.e. no forecast errors present at real time although in reality this can be nearly impossible to achieve, especially when the operation cost of frequently updating forecast is considered. Again the wind power as price taker assumption makes it logic to argue that the behaviour of the PRP on the spot market and imbalance market does not have an impact on actual spot market or imbalance prices.

It is assumed that the anonymous PRP recognized by TenneT acting on behalf of the OWEZ park (hereafter called PRP OWEZ) would nominate the predicted power output to the APX day-ahead market and submit the planned system exchange as its e-program to TenneT on a daily basis. Consequently, the PRP would receive its revenue from the APX day-ahead spot market. Assuming no optional measures taken by the PRP to incorporate its wind power forecast errors (the only possibility for this PRP would be to partly curtail the OWEZ park in case of an extreme and unpredicted surplus), TenneT would compensate all physical wind power forecast errors; consequently, the PRP would incur either a positive or negative imbalance cost associated with any deviations between the e-program and the actual delivery in real time.

In practice, under APX day-ahead, PRP OWEZ would submit the power nomination in MWh via the APX e-trading platform for each hour of the following day, where the gate closure time is 11:00 Gate closure time 
effectively requires a power prediction window of at least $13 \sim 37 \mathrm{~h}$. PRP OWEZ would also submit an e-programme specifying the output of the OWEZ park in MWh per $15 \mathrm{~min}$ to TenneT before 12:00 for each quarter hour of the following day. It is assumed that the APX nominated hourly volume is equally split between four PTUs, so TenneT's e-programme hourly sum of volume would be identical to the APX nomination hourly volume. In order to gain more insights into the impact of increased prediction accuracy upon wind power value optimization, the authors looked into two additional scenarios where the possibility of updating the nomination and e-programme to 1 and $3 \mathrm{~h}$ ahead of real-time operation was incorporated. Note that such updates are presently not common practice for Dutch PRPs with wind power as part of their portfolio.

In the model built here, the two main value components are the wind power market revenues based on energy nomination at the APX day-ahead market, and imbalance costs because of prediction error at the imbalance market. The evaluation model is based on equation (4). The revenue is normalized for each month by the total actual production. The APX average value of all hourly prices in the delivery month is defined as $\bar{P}_{\mathrm{m}, \mathrm{i}}^{\mathrm{APX}}$ for comparison.

$$
\begin{gathered}
\bar{R}=\frac{\sum_{t=1}^{N}\left(E_{\mathrm{t}}^{\mathrm{nom}} \times P_{\mathrm{t}}-E_{\mathrm{t}}^{\mathrm{err}} \times P_{\mathrm{t}}^{\mathrm{TenneT}}\right)}{\sum_{t=1}^{N} E_{\mathrm{t}}^{\mathrm{act}}} \\
E_{\mathrm{t}}^{\mathrm{nom}}=E_{\mathrm{t}}^{\mathrm{pred}} \\
E_{\mathrm{t}}^{\mathrm{err}}=E_{\mathrm{t}}^{\mathrm{act}}-E_{\mathrm{t}}^{\mathrm{pred}}
\end{gathered}
$$

where:

- $\bar{P}_{\mathrm{m}, \mathrm{i}}^{\mathrm{APX}}, \quad$ APX monthly averaged price

- $\bar{R}, \quad$ Monthly normalized revenue of the OWEZ park

- $E_{\mathrm{t}}^{\mathrm{nom}}$,

- $E_{\mathrm{t}}^{\text {pred }}$

- $E_{\mathrm{t}}^{\text {act }}$

- $E_{\mathrm{t}}^{\mathrm{err}}$

- $P_{\mathrm{t}}$

- $P_{\mathrm{t}}^{\mathrm{TenneT}}$,
OWEZ park hourly power nomination to the market for time $t$ OWEZ park power prediction for time $t$ OWEZ park power production at time $t$ Prediction error at time $t$ Price on the market at time $t$ TenneT imbalance price at time $t$, either SSP or SBP
$\left(\mathrm{EUR} \mathrm{MWh}^{-1}\right)$; $\left(\mathrm{EUR}_{\mathrm{MWh}}^{-1}\right)$; (MWh); (MWh); (MWh); (MWh); $\left(\mathrm{EUR} \mathrm{MWh}^{-1}\right)$; and $\left(\mathrm{EUR}_{\mathrm{MWh}}^{-1}\right)$.

The evaluation model consists of three steps:

- Estimate the optimal market revenue of wind power on APX, where price fluctuations have a direct impact on wind power revenue.

- Assess the sole imbalance cost at TenneT associated with energy imbalance caused by prediction error, with and without the inclusion of improved wind power forecast in the final e-programme.

- Integrate the commercial market revenue with TenneT imbalance cost to reflect the actual return of wind power.

\section{Estimation of Optimal Market Revenue on APX as a Benchmark for Modelling Results}

APX prices are determined for each hour of the day. To a large extent the price values follow a daily pattern corresponding to power demand in the system, featuring high prices during peak load hours. Hourly price incremental values largely fall within $\pm 20 \%$ of previous hourly values, as observed for $80 \%$ of the time within the analysis time frame. It is not uncommon that the hourly price differences exceed $100 \mathrm{EUR} \mathrm{MWh}^{-1}$, caused by a combination of causes such as generation outages or sudden weather changes, which are usually difficult to foresee. 
Equation (7) is used primarily to calculate the OWEZ park optimal revenue. This is later used as a benchmark against which to assess realistic OWEZ market revenues. Assuming that PRP OWEZ has a perfect forecast, the energy nomination to APX day-ahead and the e-programme submitted to TenneT are identical to actual production, delivering an imbalance cost of zero. Since the imbalance price mechanism is designed to encourage minimum energy program deviations, perfect prediction will in principle produce the optimal revenue for OWEZ park.

$$
\bar{R}_{\mathrm{APX}}^{\text {eximb }}=\frac{\sum_{t=1}^{N}\left(E_{\mathrm{t}}^{\mathrm{act}} \times P_{\mathrm{t}}^{\mathrm{APX}}\right)}{\sum_{t=1}^{N} E_{\mathrm{t}}^{\mathrm{act}}}
$$

where $\bar{R}_{\mathrm{APX}}^{\text {eximb }}$ is the OWEZ park monthly average revenue on APX $\left(\mathrm{EUR} \mathrm{MWh}^{-1}\right)$; and $P_{t}^{\mathrm{APX}}$ is the price on APX at time $t\left(\right.$ EUR $\left.\mathrm{MWh}^{-1}\right)$.

\section{Independent Imbalance Cost at the TenneT Balancing Market}

The imbalance cost incurred at TSO's balancing market independent of the complications of other self-balancing measures taken by PRP gives a good indication of the actual marginal cost across the national power generation portfolio to regain system balance from constant deviation. As aforementioned, PRP OWEZ would submit to TenneT an e-programme before 00:00 the day ahead specifying the quarterly power delivery from OWEZ park based on prediction. PRP OWEZ could use a hierarchy of prediction methods, ranging from the simplest to very complicated and expensive ones. This section gives a brief overview of different prediction methods in the industry, the method used in this paper and the prediction errors, and also explains how PRP OWEZ imbalance cost at the balancing market of TenneT TSO is calculated.

\section{Short-term Wind Power Prediction Methods}

Currently in the industry wind power prediction methods usually involve one or both of two different approaches: one is physical and the other statistical. The former is computed on a set of detailed physical parameters of the lower atmosphere and the latter is based on time series statistics aiming to find the relationship between numerical weather predictions results and online measurements. ${ }^{23,24}$ Prediction methods can be evaluated by either prediction accuracy or operational context. ${ }^{25,26,27}$ Whereas TSOs and wind power researchers value accuracy, a wind power PRP may prefer a less accurate prediction method which is easier to implement or faster to run when short-term energy nomination is frequently required. The cost of purchasing the forecast is also considered for the overall economic benefit evaluation by a PRP. ${ }^{24}$

Among many prediction methods, a very simple and frequently referred one is the persistence model, which is based on the 'what-you-see-is-what-you-get' principle and has clear advantages within the forecast window of $6 \mathrm{~h}^{28}$ It is often used as a benchmark model.

The research objective is to quantify the commodity value of the electricity output of the OWEZ park on the Dutch power market, taking into account the imbalance cost resulting from wind power prediction errors. During the research phase of the paper, the authors estimated both the most optimistic and most conservative value, thereby removing the need for a more sophisticated forecasting method and making the research results more robust. The most optimistic forecast is assumed to be achieved by most frequently updating forecast and the most conservative one by using a 'no prediction' approach with largest forecast errors. Having the 'best and worst scenarios' in mind, two variations of 'persistence' are used. The first one is 'Moving Persistence' [equation (8)] and the second one is 'Monthly Constant Output' [equation (9)].

'Moving Persistence' assumes the predicted wind power production is going to be the same as the current production, and the prediction is updated with the most recent production data at each hour. Three prediction time windows are assumed: 1, 3 and 13-37 h, the latter corresponding to APX day-ahead spot market gate closure. The 'Monthly Constant Output' is essentially equivalent to no prediction, and is expected to give the 
lowest levels of accuracy in the prediction methods hierarchy. The hourly updated persistence forecast $E_{\mathrm{t}+\mathrm{n}}$ and Monthly Constant Output prediction as a function of wind speed are given by

$$
\begin{gathered}
E_{\mathrm{t}+\mathrm{n}}^{\text {pred }}=E_{\mathrm{t}}^{\mathrm{act}} \\
E_{\mathrm{t}}^{\text {pred }}=f\left(\bar{v}, C_{\text {OWEZ }}, \rho=1.24\right)
\end{gathered}
$$

where:

- $n, \quad$ prediction window (h);

- $\bar{v}, \quad$ monthly average wind speed at the OWEZ park $\left(\mathrm{m} \mathrm{s}^{-1}\right)$;

- $C_{\text {OWEZ, }}$ power curve of OWEZ park, based on Vestas V90 and wind turbine availability (-); and

- $\rho, \quad$ air density at the OWEZ park $\left(\mathrm{kg} \mathrm{m}^{-3}\right)$.

The monthly average wind speed at the OWEZ park is listed in Table II. The authors used four random days of production data and the applied variations of persistence prediction to give an illustration of the approach, as in Figure 3. The root mean square values of forecast errors under 'Moving Persistence' are in Table III.

\section{TenneT Imbalance Cost Calculation Method}

The imbalance price settled at the TenneT balancing market is determined at the end of each PTU, when the price of the highest bid called by TenneT is known. Power imbalances of PRPs occurring within a PTU are aggregated into a total value representing the e-programme deviation of a PRP for this PTU. Thus, wind power

Table II. Wind speed $\bar{v}$ at the OWEZ park, $70 \mathrm{~m}$ above sea level ${ }^{29}$

\begin{tabular}{ccccccccc}
\hline & Oct 2006 & Nov 2006 & Dec 2006 & Jan 2007 & Feb 2007 & Mar 2007 & Apr 2007 & May 2007 \\
\hline $\bar{v}\left(\mathrm{~m} \mathrm{~s}^{-1}\right)$ & 10.5 & 10 & 10.5 & 11 & 10.5 & 9 & 8.5 & 8 \\
\hline
\end{tabular}

\section{Prediction methods for the park and concurrent production}

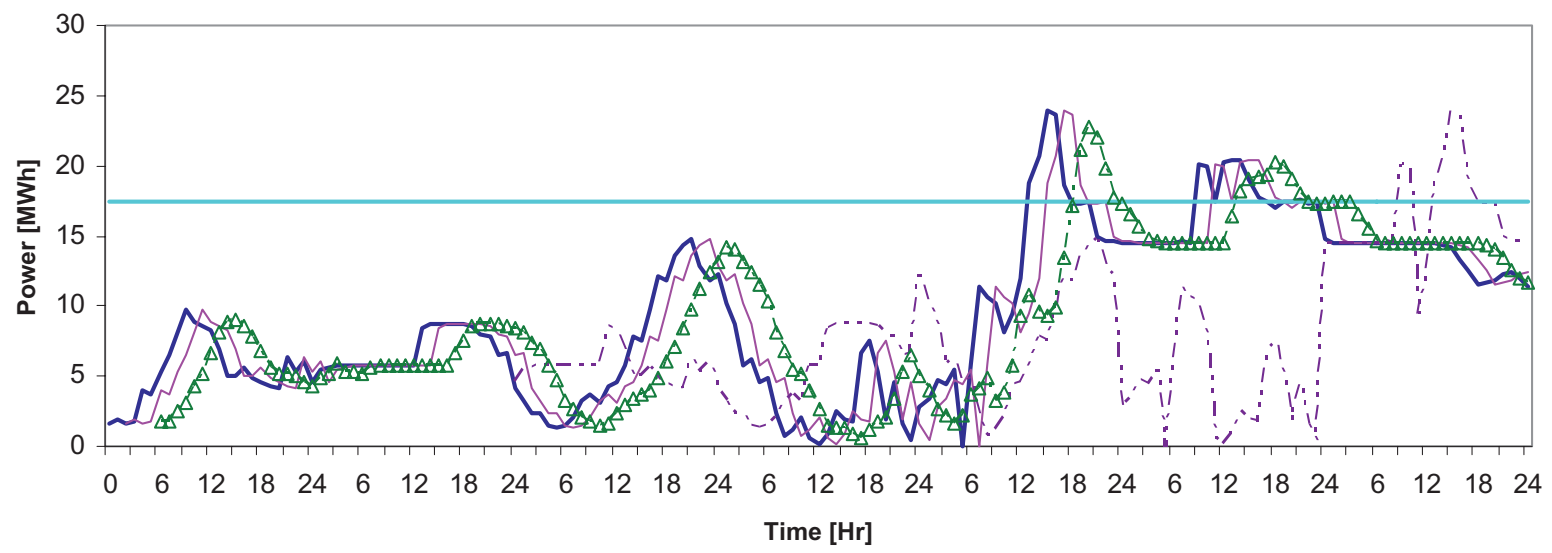

\begin{tabular}{|lll|}
\hline - Actual production & Persistence $1 \mathrm{hr}$ & $--\AA-$ Persistence $3 \mathrm{hr}$ \\
$-\cdots-$ Persistence day-ahead & Prediction constant
\end{tabular}

Figure 3. Prediction methods for the OWEZ park 
Table III. Root mean square of 'Moving Persistence' forecast errors

\begin{tabular}{lcccccccc}
\hline$(-)$ & Oct 2006 & Nov 2006 & Dec 2006 & Jan 2007 & Feb 2007 & Mar 2007 & Apr 2007 & May 2007 \\
\hline $1 \mathrm{~h}$ & 0.04 & 0.07 & 0.08 & 0.12 & 0.13 & 0.11 & 0.05 & 0.06 \\
$3 \mathrm{~h}$ & 0.08 & 0.12 & 0.12 & 0.17 & 0.19 & 0.16 & 0.14 & 0.15 \\
$\sim 13-37 \mathrm{~h}$ & 0.12 & 0.17 & 0.17 & 0.27 & 0.30 & 0.28 & 0.21 & 0.16 \\
\hline
\end{tabular}

prediction errors within a single PTU are resolved to an average value. The imbalance cost is normalized by monthly production as in equation (10).

$$
\bar{C}_{\mathrm{m}, \mathrm{i}}=\frac{\sum_{t=1}^{N}\left(E_{\mathrm{t}}^{\mathrm{err}} \times P_{\mathrm{t}}^{\mathrm{TenneT}}\right)}{\sum_{t=1}^{N} \mathrm{E}_{\mathrm{t}}^{\mathrm{act}}}
$$

if $E_{t}^{\mathrm{err}}>0$, then $P_{t}^{\mathrm{TenneT}}=S S P_{t}$;

if $E_{t}^{\text {err }}<0$, then $P_{t}^{\text {TenneT }}=S B P_{t}$.

\section{Integration Assessment Method}

The integrated evaluation of the PRP OWEZ revenue in APX Day-ahead was calculated based on

$$
\begin{gathered}
\bar{R}_{\mathrm{APX}}^{\mathrm{Int}}=\frac{\sum_{t=1}^{N}\left[E_{\mathrm{t}}^{\mathrm{nom}} \times P_{\mathrm{t}}^{\mathrm{APX}}-\sum_{p t u=1}^{4}\left(E_{\mathrm{t}, \mathrm{ptu}}^{\mathrm{err}} \times P_{\mathrm{t}, \mathrm{ptu}}^{\mathrm{TenneT}}\right)\right]}{\sum_{t=1}^{N} E_{\mathrm{t}}^{\mathrm{act}}} \\
E_{\mathrm{t}, \mathrm{ptu}}^{\mathrm{err}}=E_{\mathrm{t}, \mathrm{ptu}}^{\mathrm{act}}-\frac{1}{4} E_{\mathrm{t}}^{\mathrm{pred}}
\end{gathered}
$$

where $\bar{R}_{\mathrm{APX}}^{\text {Int. }}$ is the monthly normalized revenue on APX including imbalance (EUR MWh ${ }^{-1}$ ); and $E_{t, p t u}^{\text {err }}$ is the prediction error within PTU at hour $t$ (MWh).

Thus, the actual revenue is determined by the income yielded from the nominations made to APX less the cost of the balancing services provided by TenneT.

\section{Results and Analysis}

The following part presents the hypothetical OWEZ park values, under perfect and non-perfect forecast, generated from APX Day-ahead market from October 2006 to May 2007. Extensive analysis of the APX price distribution and forecast error distribution has also been included to give more insight to the OWEZ park value.

\section{Monthly OWEZ Optimal Value Versus APX Day-ahead Average Price}

Figure 4 shows the results of the analysis of OWEZ optimal value (i.e. the value would have achieved by nominating the actual production without forecast errors) on APX day-ahead market, in comparison with the monthly APX day-ahead average power price for the period of October 2006 to May 2007. It can be noted that for all months except October 2006, the average value of wind power is lower than the average price at 
Optimal park value on APX vs APX monthly average

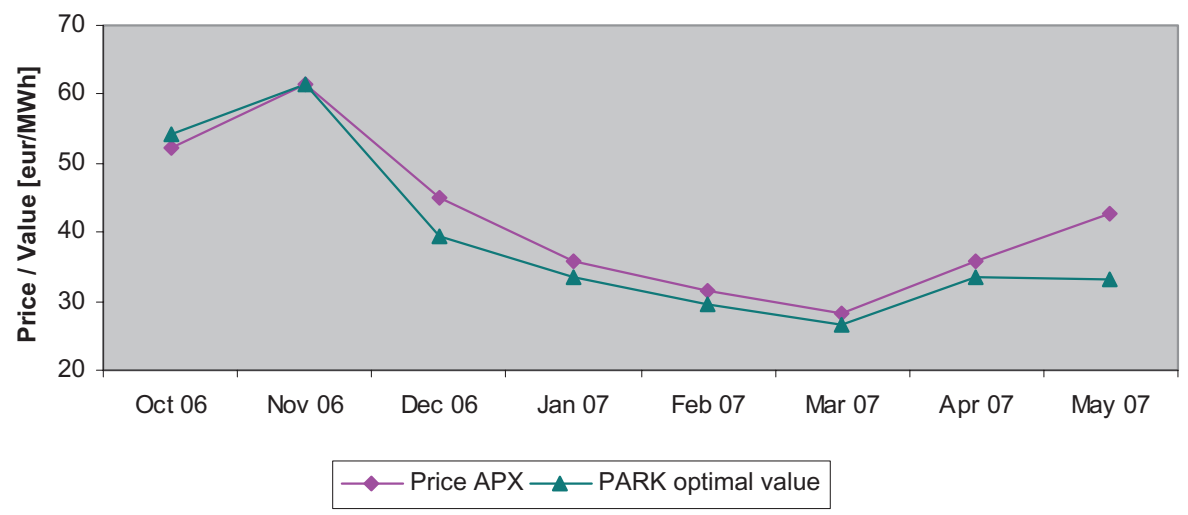

Figure 4. Energy value of OWEZ park on APX spot market excluding imbalance cost, and APX average price
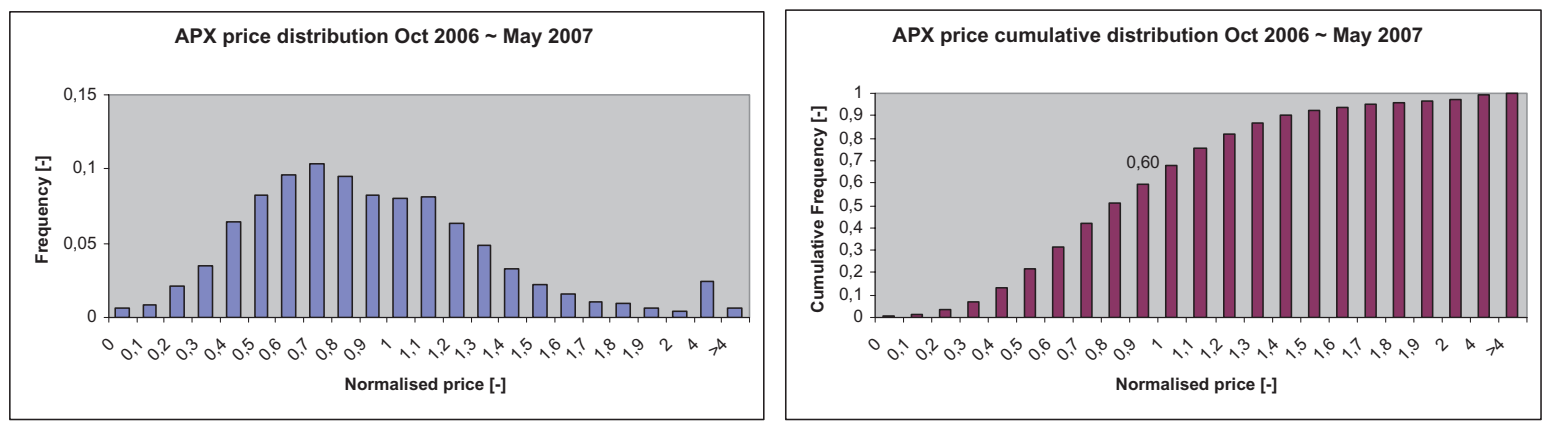

Figure 5. APX price distribution, Oct 2006 to May 2007

APX day-ahead by about $7 \%$. The value difference is in fact caused by the volatile nature of APX day-ahead price and OWEZ wind power production profile. The APX price distribution, shown in the left panel of Figure 5 as normalized compared with the hourly value using $\bar{P}_{\mathrm{m}, \mathrm{i}}^{\mathrm{APX}}$, has a characteristic right-skewed distribution. This is because of the occurrence of high price peaks at a limited number of peak-load hours. The long tail to the right distorts average prices to the right compared with an otherwise normal distribution. The graph of cumulative distribution in Figure 5 shows that the percentage (40\%) of hourly price above monthly mean price is lower than the percentage $(60 \%)$ below monthly mean price. This indicates that the power nominated to APX day-ahead by any generation sources has a higher probability to be sold during hours when the price is below the monthly average value.

The above examination means that there are three possibilities for the value of wind power output. In case the generation output would be constant, the averaged power value will be equivalent to APX day-ahead average price. In case the generation output is not constant, the power value may be higher than the average price (more production during peak than during off-peak) but it is likely to be lower (higher production during off-peak hours) considering that there are more off-peak hours than peak hours. Since the output of OWEZ is far from constant, it can be explained that OWEZ has an intrinsic lower value on APX Day-ahead than 'firm (i.e. $100 \%$ nominal availability)' generation, and that is without considering any wind power forecast errors and e-program deviations as a result of these.

Data analysis of the OWEZ delivery profile reveals in fact that more than half of the power production analysed here was produced in the hours when on APX day-ahead the hourly price was lover than daily average. 
It can be specially noted that in May 2007, OWEZ had a more pronounced low value comparatively because of the fact that more than $60 \%$ of power was produced during low priced hours.

\section{Independent Imbalance Costs on TenneT}

As aforementioned in the section Independent Imbalance Cost at the TenneT Balancing Market, the authors intended to gain an understanding of the magnitude of OWEZ imbalance cost (i.e. cost of balancing prediction errors) incurred solely at the TSO's real-time balancing market independent of the complications of other selfbalancing measures. Prices on TenneT TSO's balancing market are set independent of the wholesale platform, and are also independent of the opportunity cost that would occur to a PRP if the PRP would choose to selfbalance from own portfolio or by other market means. The results of the OWEZ imbalance cost evaluation are summarized per month and shown in Figure 6. Notably, the four prediction approaches applied in this research result in different imbalance costs, although the averaged values of the 8 month period are very close: all were lower than 2 EUR MWh ${ }^{-1}$ with the lowest value resulting from persistence $\sim 13-37 \mathrm{~h}$ ahead prediction. This value is in good accordance with another study. ${ }^{9}$ Another finding is that the imbalance costs may be positive or negative, the latter means PRP OWEZ would have been rewarded a net benefit from TSO TenneT for its forecast error, which passively contributed to restoring the power balance in the system. Moreover, the imbalance cost differs between months, with persistence 1 and $3 \mathrm{~h}$ approaches giving the least volatile values and monthly constant output resulting in the most volatile results. The cost volatility is directly related to the prediction accuracy: the larger the prediction error magnitude, the more difference between monthly imbalance costs. Figure 7 shows the forecast error normalized to predicted value for the 1, 3, 13-37 h window using persistence. For the monthly window using constant prediction, it is found that the 8 month period averaged values of imbalance cost under four prediction variations are very close to each other. This indicates that in the longer term (several months to annual), imbalance costs are not very sensitive to the magnitude of the prediction errors. The prediction accuracy differs largely from one approach to another, whereas the averaged imbalance cost does not vary much. This is because within the national power system, the capacity available $\left(500 \mathrm{MW}^{11}\right)$ for power regulation is sufficient to match OWEZ prediction errors at all times. Certainly, these results provide evidence that the imbalance costs of OWEZ are very low, which can be explained by the low wind penetration level in The Netherlands.

\section{PARK imbalance costs on TenneT 4 different prediction windows}

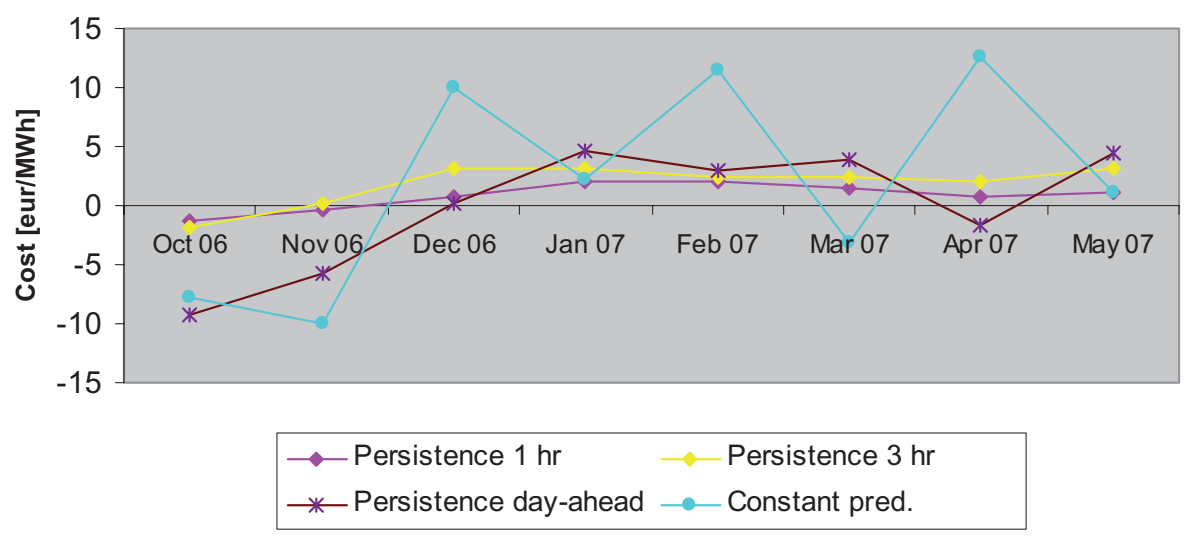

Figure 6. OWEZ park imbalance costs for four prediction windows 


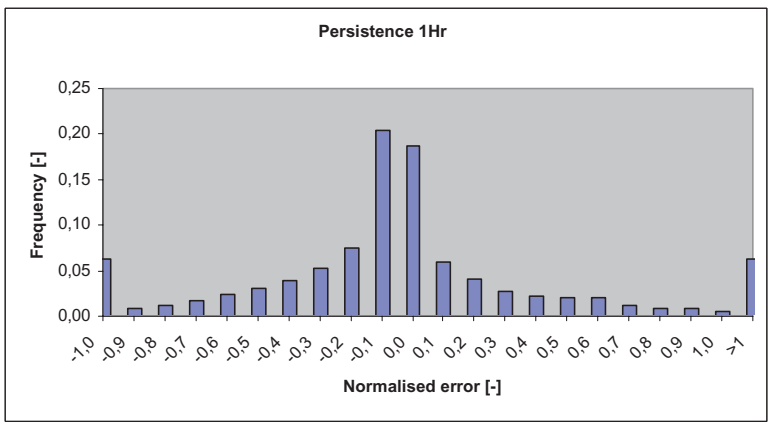

Persistence Day-ahead

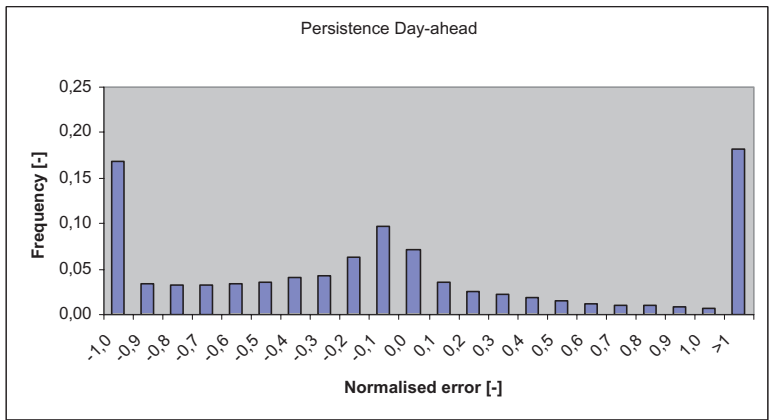

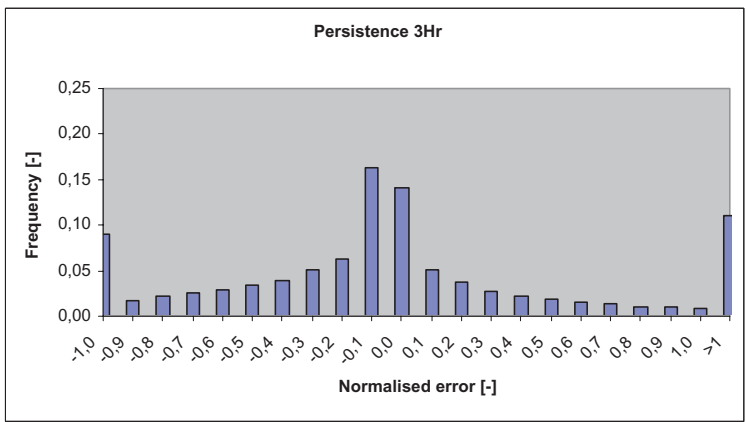

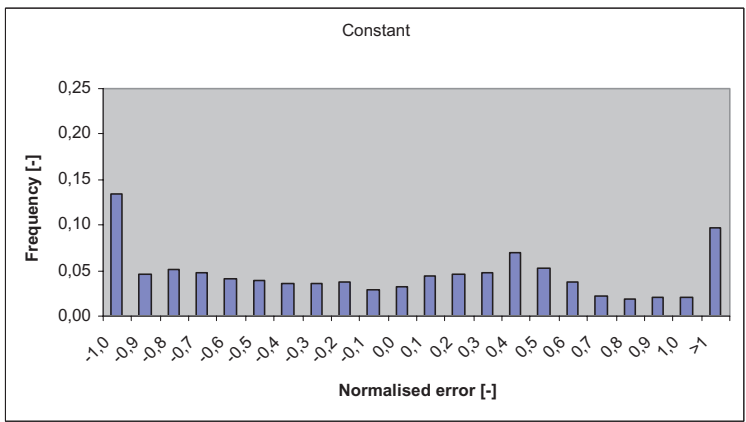

Figure 7. Prediction error distributions for four prediction windows for the OWEZ park

\section{Integrated Evaluation}

The commodity value of the OWEZ output is approximated by combining the revenues from nominating this output to APX day-ahead and the imbalance cost. The revenues are based on the four forecasting methods of the OWEZ output while the imbalance costs are derived from combining the forecasts with the actual power output and the imbalance prices. The timely price spread between the APX and TenneT real-time balancing market affects the economics of forecasting error. The results of this integrated evaluation are presented in Figure 8.

First observation of Figure 8 is that the four integrated values are very close, although a larger price difference ( $>5 \mathrm{EUR} \mathrm{MWh}^{-1}$ ) applies for the months October, November 2006, and May 2007. Secondly, all monthly values fall in the range of $90 \sim 110 \%$ of monthly averaged APX day-ahead hourly prices. Third observation is that the optimal value without forecasting errors is not necessarily the highest for all months, which implies that forecast errors can be commercially beneficial at times. This is because forecast errors may actually result in additional income for the PRP, a result similar to other studies. ${ }^{30,31}$ Furthermore, contrary to what was assumed that the least prediction error would generate the most economic value, the highest OWEZ value resulted from persistence day-ahead prediction of which the prediction accuracy was next to the lowest, instead of a $1 \mathrm{~h}$ persistence prediction, which had the highest accuracy. The Monthly Constant Prediction method, being the least accurate, yielded the second-highest OWEZ park value. Imbalance cost is frequently referred to as an imbalance penalty from the perspective of a PRP. The results obtained here suggest to what extent forecast errors could be viewed indeed as a net penalty. If at time periods when a forecasting error is in an opposite direction to the imbalance of the national power system and the national power system has assigned higher price to the balancing input than the same time APX day-ahead price, forecast errors can bring commercial benefit to a PRP. The impact of imbalance costs on overall economic value of wind power can be either positive or negative and should be determined by a thorough analysis of the overall power system's position in real-time (long or short) and the bid prices set ex-post at the imbalance market. Notably, trade-offs may be possible between nominations on the APX spot market anticipating a position on TenneT's imbalance 


\section{Integrated park power value on APX}

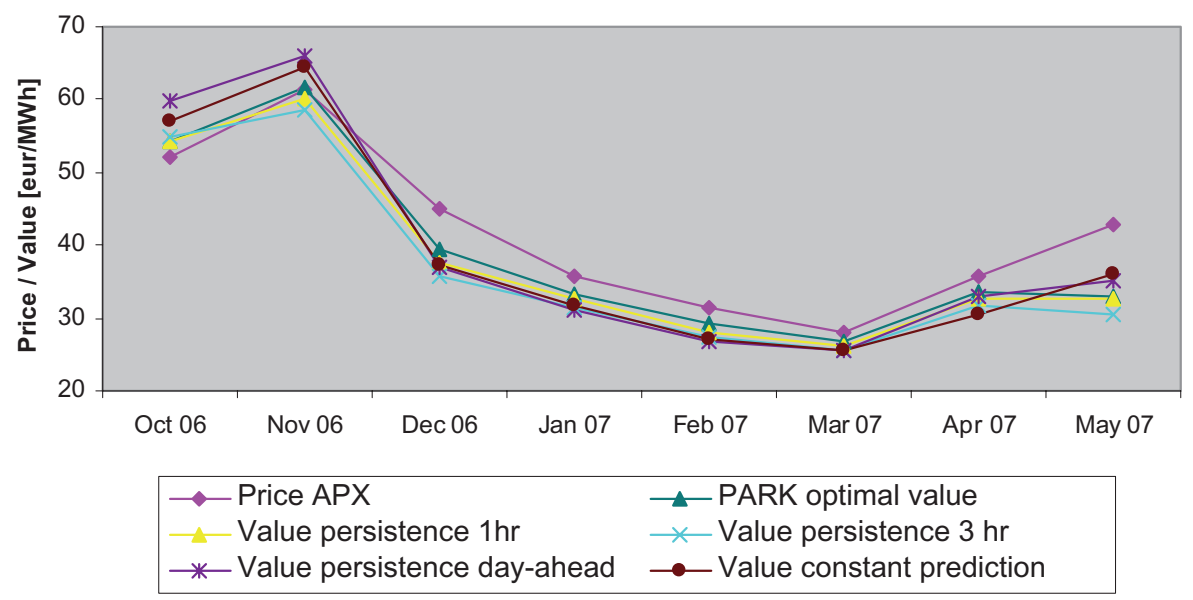

Figure 8. OWEZ park power values on APX under four prediction/nomination methods

market in order to maximize overall profit. However, the authors do not intend to state that a forecasting method with higher forecasting errors is necessarily commercially beneficial, and from a power system secure and reliable operation perspective, the use of such method should be discouraged.

Finally, it must be noted that the prices at the imbalance market are strongly influenced by the operation strategy of the PRPs. At present, Dutch PRPs have a rather risk-averse attitude and prefer to keep individual power reserves for minimization of e-programme deviations, rather than buying from and selling to TenneT at imbalances prices unknown on beforehand. Taking into account that the separate PRP assumed in this research would in fact have an impact on actual imbalance prices, also the operational strategy of other PRPs may be changed. Furthermore, with additional wind power on the horizon, correlations between wind power output and imbalance prices may increase. Clearly, the approach taken in this paper is not applicable for largescale wind power integration.

\section{Conclusions}

In this paper, a straightforward approach is used for the economic evaluation of market integration of wind power, taking a $108 \mathrm{MW}$ offshore wind park in the liberalized Dutch market as a case study. It is found that at the current wind penetration level, correlations between wind power supply and market prices are insignificant, i.e. wind power is a price taker on the market. Also, 8 month averaged imbalance costs at the real-time balancing market are insensitive to wind power prediction errors. Even though wind power prediction errors may influence the momentary physical market position of an individual market party ('long' or 'short'), these errors do not result in actual costs or revenues for the associated market party. As long as wind power continues to be a price taker, the imbalance costs resulting from wind power forecast errors should therefore be regarded as low.

It is concluded that the commercial value of wind power in the Dutch market is presently determined only by its production profile measured against short-term market prices. For the period investigated, the rightskewed distribution of APX Day-ahead market prices in combination with wind power's availability is found to reduce the market value of wind power by $7-10 \%$ compared with the value of conventional generation.

Although not a determining element of longer-term wind power value, wind power prediction errors are shown to have an impact on the short-term cost/revenue distribution between the 'balancing' market and APX day-ahead market. From the point of view of an individual market player with a given generation portfolio, 
large prediction errors may result in significant opportunity losses. Although primarily offset by the revenues on the short-term wholesale market achieved with prior nomination, the magnitude of imbalance cost affects the financial risk of an individual market party on both markets and therefore should be reduced.

\section{Recommendations}

The impact of wind power on short-term market prices will increase with the wind power penetration level, as well as the absolute magnitude of prediction errors. Additional power reserves will be required and the market risk of individual market players with wind power in their portfolio will be increased. Additional efforts are needed in order to improve wind power prediction accuracy on the day-ahead and shorter time-scales, especially considering targets in place for wind power. The price-taker assumption, although demonstrated in this paper, will be applicable only on up to a certain wind power penetration level.

The right-skewedness of the Dutch short-term market price profile enhances the power value of generation capacity available at strongly demanded time points, thereby encouraging 'firmness' of generation at peak hours. The market value of power from the offshore park investigated in this paper has been found to be less than that of 'firm' generation; however, combinations of offshore and onshore parks may offer optimization and firmer availability of power due to different offshore and onshore wind patterns. Also geographical correlations between different wind park sites should be considered when assessing the added value of wind power. This could be achieved either by regulation (e.g. by exempting wind power operators from the obligation to submit energy programmes, thus effectively laying the balancing obligation in the hands of the system operator), or by portfolio management of wind power operators in a liberalized market.

It is the authors' belief that in fully liberalized markets, wind power should be regarded as an integral part of a market party's generation portfolio and trading strategy, and that clear and transparent price signals should be available to all market participants. This makes it possible for market parties to create value from situations in which the reserve market, their conventional generation portfolio and/or wind power is either long or short. An active attitude towards the market integration of wind power would facilitate more balanced wind power supply agreements with wind park developers and thereby enable the further growth of wind power.

\section{References}

1. The European Wind Energy Association report 2007. [Online]. Available: http://www.ewea.org/publications/reports. (Accessed 12 June 2007).

2. Global Wind Energy Council. Press Release 6 February 2008: US, China \& Spain lead world wind power market in 2007. [Online]. Available: http://www.gwec.net/news. (Accessed 12 June 2007).

3. Ummels BC, Gibescu M, Kling WL, Paap GC. Market integration of wind power in the Dutch liberalised market. Wind Energy 2006; 9: 579-590.

4. Fabbri A, Gomez San Roman T, RivierAbbad J, MendezQuezada VH. Assessment of the cost associated with wind generation prediction errors in a liberalized electricity market. IEEE Transactions on Power Systems 2005; 20: 14401446.

5. Angarita-Márquez JL, Hernandez-Aramburo CA, Usaola-Garcia J. Analysis of a wind farm's revenue in the British and Spanish markets. Energy Policy 2007; 35: 5051-5059.

6. Swider DJ, Beurskens L, Davidson S, Twidell J, Pyrko J, Prüggler W, Auer H, Vertin K, Skema R. Conditions and costs for renewables electricity grid connection: Examples in Europe. Renewable Energy 2008; 33: 1832-1842

7. Dale L, Milborrow D, Slarkc R, Strbac G. Total cost estimates for largescale wind scenarios in UK. Energy Policy 2004; 32:1945-1956.

8. Holttinen H. Handling of wind power forecast errors in the Nordic power market. Proceedings: Probabilistic Methods Applied to Power Systems 2006, Stockholm, Sweden 11-15 June 2006.

9. Holttinen H, Meiborn P, Ensslin C, Hofmann L, McCann J, Pierik J, Tandez JO, Hagstrom E, Estanqueiro A, Amaris H, Soder L, Strbac G, Parsons B. Design and operation of power systems with large amounts of wind power, Stateof-the-art report. October 2007, IEA Task 25 Publications. [Online]. Available: http://www.ieawind.org/AnnexXXV. html.

10. Official website of Offshore Wind park Egmond aan Zee. [Online]. Available: http://www.noordzeewind.nl. (Accessed 2 January 2007). 
11. Dutch TSO TenneT System Services. Programme Responsibility, Energy Programme. [Online]. Available: http://www. tennet.org/english/transmission_system_services/system_services/programme_responsibility/index.aspx. (Accessed 8 January 2007).

12. Wind Service Holland. [Online]. Available: http://home.planet.nl/ windsh/. (Accessed 12 February 2008).

13. Brinkhorst LJ, The Minister of Economic Affairs, the Netherlands. Address at the Wind Offshore Conference, Egmond aan Zee, 30 September 2004. [Online]. Available: http://www.ez.nl/actueel/toespraken/. (Accessed 17 February 2007).

14. Flores P, Tapia A, Tapia G. Application of a control algorithm for wind speed prediction and active power generation. Renewable Energy 2005; 30: 523-536.

15. Holttinen $\mathrm{H}$. The impact of large scale wind power production on the Nordic electricity system. VTT Technical Research Centre of Finland, VTT Publications 554, 2004.

16. Bode S. On the impact of renewable energy support schemes on power prices. Hamburg Institute of International Economics, 2006. [Online]. Available: http://www.hwwi.org/uploads/tx_wilpubdb/HWW1_Research_Paper_4-7.pdf.

17. Energinet. DK Transmission System Operator Denmark. System Plan 2007. [Online]. Available: http://www.energinet. $\mathrm{dk} / \mathrm{en} / \mathrm{menu} /$ Planning/System+planning/The+System+Plan+2007.htm.

18. E.ON Netz GmbH, Transmission System Operator Germany. Wind Report 2005. [Online]. Available: http://eon-netz. com/Resources/downloads/Eon_Netz_Windreport2005_eng.pdf.

19. Glachant JM, Saguan M. An institutional frame to compare alternative market designs in EU electricity balancing. Cambridge Working Papers in Economics 2007, Faculty of Economics, University of Cambridge, 2007.

20. Focken U, Lange M, Monnich K, Waldl H. Short-term prediction of the aggregated power output of wind farms-a statistical analysis of the reduction of the prediction error by spatial smoothing effects. Journal of Wind Engineering \& Industrial Aerodynamics 2002; 90: 231-246.

21. Nanahara T, Asari M, Maejima T, Sato T, Yamaguchi K, Shibata M. Smoothing effects of distributed wind turbines part 2: coherence among power output of distant wind turbines. Wind Energy 2004; 7: 75-85.

22. Gibescu M, Ummels BC, Kling WL. Statistical wind speed interpolation for simulating aggregated wind energy production under system studies. Proceeding in 9th International Conference on Probabilistic Methods Applied to Power Systems, Stockholm, Sweden, 2006

23. Giebel G, Brownsword R, Kariniotakis G. The State-Of-The-Art in Short-Term Prediction of Wind Power: A Literature Overview. Ris $\emptyset$ National Laboratory: Denmark, 2003.

24. Kariniotakis G, Pinson P, Siebert N, Giebel G, Barthelmie R. The State of the Art in Short-term Prediction of Wind Power-From an Offshore Perspective. In proceedings of 2004 SeaTechWeek, 18-22 October 2004, Brest, France: 20-21.

25. Madsen H, Kariniotakis G, Nielsen HA, Nielsen TS, Pinson P. Standardising the performance evaluation of short-term wind power prediction models. Wind Engineering 2005; 29:475-489.

26. Pinson P. Estimation of the Uncertainty in Wind Power Forecasting. Energetique. MINES de Paris: Paris, 2006.

27. Barthelmie RJ, Murray F, Pryor SC. The economic benefit of short-term forecasting for wind energy in the UK electricity market. Energy Policy 2008; 36:1687-1696.

28. Landberg L. Short-term prediction of the power production from wind farms. Journal of Wind Engineering and Industrial Aerodynamics 1999; 80:207-220.

29. Coelingh JP, van Zuylen EJ. Wind Speed Prediction Egmond. Ecofys: Utrecht, The Netherlands, 2001.

30. Fabbri A, GomezSanRoman T, RivierAbbad J, MendezQuezada VH. Assessment of the cost associated with wind generation prediction errors in a liberalized electricity market. IEEE Transactions on Power Systems 2005; 20: 14401446.

31. DeMeo EA, Grant W, Milligan MR, Schuerger MJ, Wind plant integration: costs, status and issues. IEEE Power and Energy Magazine 2005; 3: 38-46. 